\title{
Timing and Associated Factors for Sepsis-3 in Severe Trauma Patients: A 3-Year Single Trauma Center Experience
}

\author{
Seungwoo Chung, Donghwan Choi, Jayun Cho, Yo Huh, Jonghwan Moon, Junsik Kwon, Kyoungwon Jung, \\ John-Cook Jong Lee, Byung Hee Kang
}

Department of Surgery, Ajou University School of Medicine, Suwon, Korea

Background: We hypothesized that the recent change of sepsis definition by sepsis-3 would facilitate the measurement of timing of sepsis for trauma patients presenting with initial systemic inflammatory response syndrome. Moreover, we investigated factors associated with sepsis according to the sepsis-3 definition.

Methods: Trauma patients in a single level I trauma center were retrospectively reviewed from January 2014 to December 2016. Exclusion criteria were younger than 18 years, Injury Severity Score (ISS) $<15$, length of stay $<8$ days, transferred from other hospitals, uncertain trauma history, and incomplete medical records. A binary logistic regression test was used to identify the risk factors for sepsis-3.

Results: A total of 3,869 patients were considered and, after a process of exclusion, 422 patients were reviewed. Fifty patients (11.85\%) were diagnosed with sepsis. The sepsis group presented with higher mortality $(14[28.0 \%]$ vs. $17[4.6 \%], \mathrm{P}<0.001)$ and longer intensive care unit stay ( 23 days [range, 11 to 35 days] vs. 3 days [range, 1 to 9 days], $\mathrm{P}<0.001$ ). Multivariate analysis demonstrated that, in men, high lactate level and red blood cell transfusion within 24 hours were risk factors for sepsis. The median timing of sepsis-3 was at 8 hospital days and 4 postoperative days. The most common focus was the respiratory system.

Conclusions: Sepsis defined by sepsis-3 remains a critical issue in severe trauma patients. Male patients with higher ISS, lactate level, and red blood cell transfusion should be cared for with caution. Reassessment of sepsis should be considered at day 8 of hospital stay or day 4 postoperatively.

Key Words: intensive care units; risk factors; sepsis; wound and injuries

\section{INTRODUCTION}

Trauma deaths typically occur within 48 hours of traumatic events, but the occurrence of sepsis is a major concern in trauma patients who have survived initial resuscitation [1]. Several published studies have identified risk factors for sepsis in trauma patients and have suggested that injury severity was the most common risk factor, although in rare cases, modifiable risk factors exist [2-4].

Sepsis-3 was recently defined as life-threatening organ dysfunction caused by a dysregu-

\section{Original Article}

Received: March 23, 2018

Revised: May 15, 2018

Accepted: May 21, 2018

Corresponding author Byung Hee Kang

Department of Surgery, Ajou University School of Medicine, 206 World cup-ro, Yeongtong-gu, Suwon 16499, Korea

Tel: +82-31-219-7764

Fax: +82-31-219-7781

E-mail:kbhname@gmail.com

Copyright (@) 2018 The Korean Society of Critical Care Medicine

This is an Open Access article distributed under the terms of Creative Attributions Non-Commercial License (http:// creativecommons.org/li-censes/by-nc/4.0/ which permits unrestricted noncommercial use, distribution, and reproduction in any medium, provided the original work is properly cited. 
lated host response to infection [5]. For this new definition, the Sequential Organ Failure Assessment (SOFA) score or quick SOFA (qSOFA) score was utilized [6]. Before the change in definition, systemic inflammatory response syndrome (SIRS) caused by infection was diagnosed as sepsis [7]. It was difficult to detect the timing of sepsis in trauma patients because severely injured patients usually presented with SIRS. However, it might be easier to detect sepsis using the sepsis-3 definition because severely injured patients are usually admitted to intensive care units (ICUs) for continuous monitoring with serial blood tests. The SOFA score and signs of infection are likely to be noticed during daily rounds. The purpose of the present study was to investigate the timing of the development of sepsis, defined by sepsis-3 criteria, and to identify the associated factors for sepsis occurrence in patients after severe trauma.

\section{MATERIALS AND METHODS}

\section{Study Population}

From January 2014 to December 2016, trauma patients in Ajou University Hospital Trauma Center were retrospectively reviewed. To identify severely injured patients, patients with Injury Severity Score (ISS) $<15$ were excluded. For monitoring of sepsis development, patients with a length of stay (LOS) $<8$ days were also excluded. Other exclusion criteria were as follows: under the age of 18 years, transferred from other hospitals, uncertain trauma history, and incomplete medical records (Figure 1). This study was performed according to the Helsinki Declaration and approved by the Institutional Review Board of Ajou Medical Center (IRB No. AJIRB-MEDMDB-17-464).

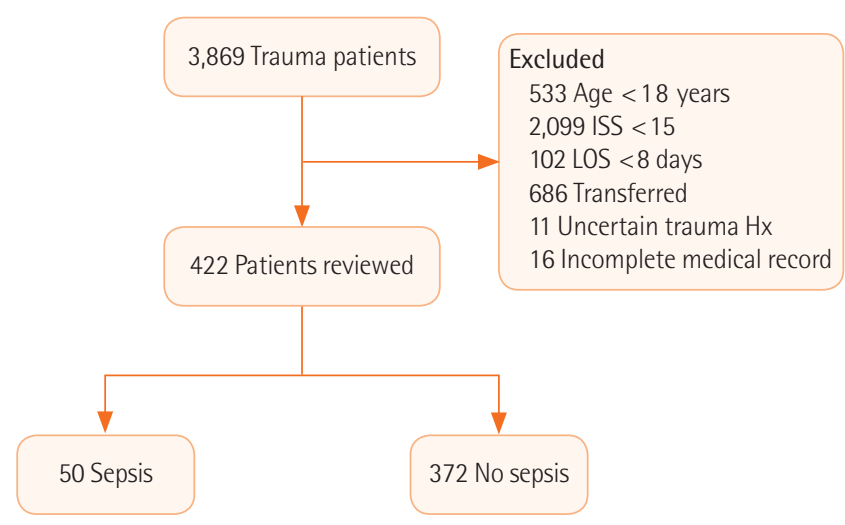

Figure 1. Flow diagram of patient enrollment. ISS: Injury Severity Score; LOS: length of stay; Hx: history.

\section{KEYMESSAGES}

- Sepsis was associated with poor outcomes in trauma patients who have survived during initial period.

- Around 8 days of hospital admission or 4 days of postoperation, we should pay attention to sepsis.

\section{Definitions}

Sepsis-3 was defined as an increase of 2 or more points in the SOFA or qSOFA score due to infection. Infection was identified by image study, culture study, medical record, or opinion of an infection specialist. Sepsis-3 was monitored during total LOS in the hospital. Vital signs, Glasgow Coma Scale (GCS), and lactate level were measured when patients arrived at the hospital. Revised Trauma Score (RTS) was calculated based on GCS, systolic blood pressure, and respiratory rate. SIRS was defined based on initial vital signs and laboratory findings. Wounds were divided into four groups: abrasions, lacerations (subcutaneous deep), open wound (muscle-deep), or open wound (bone-deep). Antibiotics were considered to be any kind of antibiotics given in the emergency room.

\section{Statistical Analysis}

Continuous data were presented as median values and interquartile ranges, and categorical data were presented as frequencies and percentages. Comparisons were performed using the Mann-Whitney U-test for continuous variables and the chi-square analysis for categorical variables. Variables, selected after univariate analysis with $\mathrm{P}<0.10$, were included in the multivariate analysis by applying binary logistic regression based on the forward selection (conditional) method, but overlapping variables were not selected. The results of the binary logistic analyses were summarized by estimating the odd ratio and the respective 95\% confidence intervals. All analyses were performed using IBM SPSS version 21.0 (IBM Corp., Armonk, NY, USA).

\section{RESULTS}

\section{Patient Characteristics}

A total of 3,869 patients were included, and after a process of exclusion, 422 patients were reviewed. Fifty patients (11.8\%) were diagnosed with sepsis-3 and 372 patients were not. Demographic characteristics are shown in Table 1. The sepsis-3 group had a higher mortality rate $(28.0 \%$ vs. $4.6 \%, \mathrm{P}<0.001)$ and greater ICU LOS (23 days [range, 11 to 35 days] vs. 3 days [range, 1 to 9 days], $\mathrm{P}<0.001$ ). 
Table 1. Demographics and clinical characteristics of severe trauma patients

\begin{tabular}{|c|c|c|c|}
\hline Variable & $\begin{array}{l}\text { Sepsis } \\
(n=50)\end{array}$ & $\begin{array}{l}\text { No sepsis } \\
(n=372)\end{array}$ & P-value \\
\hline Age (yr) & $52(40-62)$ & $48(34-59)$ & 0.244 \\
\hline Male sex & $45(90.0)$ & $288(77.4)$ & 0.041 \\
\hline $\begin{array}{l}\text { Injury mechanism } \\
\text { Blunt } \\
\text { Penetrating }\end{array}$ & $\begin{array}{c}49 \text { (98.0) } \\
1(2.0)\end{array}$ & $\begin{array}{c}358(96.2) \\
14(3.8)\end{array}$ & 0.527 \\
\hline $\begin{array}{l}\text { Medical history } \\
\text { Cardiogenic } \\
\text { Respiratory } \\
\text { Gastrointestinal } \\
\text { Endocrine } \\
\text { Renal } \\
\text { Neurologic }\end{array}$ & $\begin{array}{c}21(42.0) \\
13(26.0) \\
2(4.0) \\
1(2.0) \\
7(14.0) \\
1(2.0) \\
3(6.0)\end{array}$ & $\begin{array}{c}141(37.9) \\
88(23.7) \\
13(3.5) \\
7(1.9) \\
56(15.1) \\
4(1.1) \\
27(7.3)\end{array}$ & $\begin{array}{l}0.576 \\
0.715 \\
0.856 \\
0.954 \\
0.844 \\
0.570 \\
0.745\end{array}$ \\
\hline Systolic BP (mmHg) & $112(90-130)$ & $126(102-144)$ & 0.021 \\
\hline Diastolic BP (mmHg) & $70(60-82)$ & $80(62-90)$ & 0.114 \\
\hline Pulse rate (/min) & $102(84-125)$ & $88(77-100)$ & $<0.001$ \\
\hline Respiratory rate (/min) & $20(16-30)$ & $17(15-21)$ & $<0.001$ \\
\hline ISS & $27(22-38)$ & $22(17-27)$ & $<0.001$ \\
\hline RTS & $6.61(5.68-7.84)$ & $7.84(6.55-7.84)$ & $<0.001$ \\
\hline GCS & $10(7-15)$ & $15(10-15)$ & $<0.001$ \\
\hline Emergency operation & $36(72.0)$ & 200 (53.8) & 0.015 \\
\hline Operation number & $3(1-4)$ & $1(1-3)$ & $<0.001$ \\
\hline Diagnosed SIRS at initial & $42(84.0)$ & $238(64.0)$ & $<0.001$ \\
\hline Initial lactate (mmol/L) & $4.68(2.95-6.15)$ & $2.78(1.89-3.70)$ & $<0.001$ \\
\hline RBC transfusion (U/day) & $9(2-22)$ & $1(0-4)$ & $<0.001$ \\
\hline FFP transfusion (U/day) & $7(0-19)$ & $0(0-3)$ & $<0.001$ \\
\hline $\begin{array}{l}\text { Wound } \\
\text { None } \\
\text { Abrasion } \\
\text { Laceration } \\
\text { Open wound }\end{array}$ & $\begin{array}{r}10(20.0) \\
7(14.0) \\
20(40.0) \\
13(26.0)\end{array}$ & $\begin{array}{r}115(30.9) \\
71(19.1) \\
122(32.8) \\
64(17.2)\end{array}$ & 0.176 \\
\hline Antibiotics in ER & 44 (88.0) & 265 (71.2) & 0.001 \\
\hline Initial SOFA score & $1(0-3)$ & $3(1-5)$ & $<0.001$ \\
\hline Mortality & $14(28.0)$ & $17(4.6)$ & $<0.001$ \\
\hline ICU LOS (day) & $23(11-35)$ & $3(1-9)$ & $<0.001$ \\
\hline
\end{tabular}

Values are presented as median (interquartile range) or number (\%). BP: blood pressure; ISS: Injury Severity Score; RTS: Revised Trauma Score; GCS: Glasgow Coma Scale; SIRS: systemic inflammatory response syndrome; RBC: red blood cell; FFP: fresh frozen plasma; ER: emergency room; SOFA: Sequential Organ Failure Assessment; ICU: intensive care unit; LOS: length of stay.

\section{Associated Factors for Sepsis-3}

Sex, emergency operation, SIRS, antibiotics, GCS, ISS, transfusion, lactate, blood pressure, pulse rate, respiratory rate, and RTS were significantly different between the two groups. Sex, emergency operation, use of antibiotics, ISS, red blood cell
Table 2. Independent associated factors for sepsis after severe trauma

\begin{tabular}{lcc}
\hline Variable & Odds ratio $(95 \% \mathrm{CI})$ & P-value \\
\hline Male sex & $3.254(1.009-10.493)$ & 0.048 \\
Lactate & $1.181(1.028-1.357)$ & 0.019 \\
ISS & $1.062(1.024-1.102)$ & 0.001 \\
RBC transfusion & $1.061(1.028-1.094)$ & $<0.001$ \\
\hline
\end{tabular}

Cl: confidence interval; ISS: Injury Severity Score; RBC: red blood cell.

Table 3. Timing and focus of sepsis in severe trauma patients

\begin{tabular}{lc}
\hline Variable & Value \\
\hline Timing of sepsis & \\
Hospital day & $8(6-11)$ \\
Postoperative day & $4(3-6)$ \\
Focus of sepsis & \\
Respiratory system & $33(66.0)$ \\
Intra-abdomen & $7(14.0)$ \\
Surgical wound & $6(12.0)$ \\
Catheter-related & $3(6.0)$ \\
Unknown & $1(2.0)$ \\
\hline
\end{tabular}

Values are presented as median (interquartile range) or number (\%).

(RBC) transfusion, lactate, and RTS were selected for multivariable analysis because vital signs, including SIRS and GCS, overlapped with RTS. After multivariable analysis, male sex, lactate, ISS, and RBC transfusion were selected as associated factors for sepsis-3 (Table 2).

\section{Timing and Focus of Sepsis}

Among 50 patients in the sepsis group, no operation was performed in 10 patients. In all patients, the median timing of sepsis-3 was at 8 hospital days (range, 6 to 11 days). In patients who had undergone surgery, median timing of sepsis-3 was 4 postoperative days (range, 3 to 6 days) from the last surgery. The most common cause of sepsis involved the respiratory system (66.0\%). One case presented with Escherichia coli in the blood, but the focus was not found. After antibiotic therapy without surgical debridement, the patient survived (Table 3 ).

\section{DISCUSSION}

Sepsis-3 was associated with poor prognoses in trauma patients, and male sex, lactate, ISS, and RBC transfusion were associated factors for sepsis-3 in the current study. Sepsis-3 occurred in $11.8 \%(n=50)$ of the study patients, and the inhospital mortality rate was $28.0 \%(n=14)$ for the sepsis-3 patients. Park et al. [8] demonstrated that the incidence of sepsis- 2 was $8.2 \%$ and mortality was $6.7 \%$ in trauma patients (ISS 
$>8$ ) in the same country as our study. Sepsis-3 is more specific than the previous sepsis-2 definition because organ failure should be noticeable in sepsis [9]. Nevertheless, the incidence and mortality of sepsis-3 were higher in the current study because more severe patients (ISS $\geq 16$ ) were included. Moreover, Shankar-Hari et al. [10] demonstrated that mortality with sepsis-3 in the ICU was $22.4 \%$. Besen et al. [11] demonstrated that ICU mortality of patients with sepsis-3 was $25 \%$ and septic shock was $46 \%$ in low-middle-income countries, which were more severe than the mortality of patients with sepsis-2 (severe sepsis, 17\%; septic shock, 44\%). Although our study did not distinguish between septic shock and non-septic shock groups, mortality was similar in our study to that reported in these studies.

Kisat et al. [2] demonstrated that age, male sex, AfricanAmerican race, hypotension, and motor vehicle crash were risk factors for sepsis in trauma patients. Osborn et al. [3] reported that ISS, RTS, admission GCS, and comorbid conditions (i.e., diabetes, cardiac disease, and immune disorder) were independent predictors of sepsis. Increased ISS was also significantly associated with the clinical outcome of sepsis patients. Wafaisade et al. [4] reported that male sex, ISS, operative procedure, RBC transfusion, GCS, and age were risk factors for sepsis. Similar to previous studies, male sex, lactate, ISS, and RBC transfusion were selected as associated factors for sepsis-3 in our study. Injury severity was correlated with immune system, and lactate level reflected the severity of trauma [12,13]. In large studies, male sex was associated with sepsis, which could be attributed to genetic or socioeconomic factors $[14,15]$. The ISS and male sex were common risk factors for sepsis that cannot be modified. However, RBC transfusion is modifiable if bleeding is controlled early. Therefore, early bleeding control might be considered to reduce the risk of sepsis.

Forty-two of 50 patients (84.0\%) who were diagnosed with sepsis-3 presented with initial SIRS in this study. In addition, most patients presented with SIRS during admission because trauma patients usually require surgical or invasive procedures. Hence, it was difficult to distinguish between SIRS caused by trauma or by infection. The SOFA score can also be affected by trauma or by surgery; nevertheless, sepsis-3 might make it easier to define the timing of sepsis. If the patient is diagnosed with the septic condition and infection at some point, the timing of sepsis could be defined by retrospective review of vital signs and SOFA scores.

The respiratory system was the most common focus of sepsis in ICU patients [16]. Quenot et al. [17] demonstrated that
$53.6 \%$ of ICU patients had respiratory infection as the cause of septic shock. In concordance with the previous study, the respiratory system was the most common focus in our study, with $66.0 \%$ of patients having respiratory infection as the cause of septic shock. The patients in this group received more operations, and ventilator care was usually required after surgery. Because prolonged mechanical ventilation increased the risk of respiratory infection in trauma patients [18], early weaning from ventilators via early operation should be considered.

Our study had several limitations. First, this study was retrospective in design and the number of patients was not sufficient. Second, the timing of sepsis is a matter of "hours" not "days." Third, because some patients were diagnosed with sepsis in the general ward, the timing of sepsis might have been delayed.

In conclusion, sepsis-3 has critical effects in severe trauma patients. Male sex, ISS, lactate, and RBC transfusion were associated with sepsis. Unlike other associated factors, RBC transfusion is a modifiable risk factor. Efforts to reduce RBC transfusion are needed. Additionally, assessment for sepsis should be considered at day 8 in hospital or day 4 postoperative in order to better identify sepsis-3 timing.

\section{CONFLICT OF INTEREST}

No potential conflict of interest relevant to this article was reported.

\section{ORCID}

Seungwoo Chung http://orcid.org/0000-0003-3774-6933

Donghwan Choi http://orcid.org/0000-0001-7596-4371

Yo Huh http://orcid.org/0000-0002-1220-1534

Jonghwan Moon ～http://orcid.org/0000-0002-4630-3301

Junsik Kwon http://orcid.org/0000-0003-3164-4995

Kyoungwon Jung ～http://orcid.org/0000-0001-7895-0362

John-Cook Jong Lee http://orcid.org/0000-0002-5468-3340

Byung Hee Kang http://orcid.org/0000-0003-3204-3251

\section{REFERENCES}

1. Sauaia A, Moore FA, Moore EE, Moser KS, Brennan R, Read RA, et al. Epidemiology of trauma deaths: a reassessment. J Trauma 1995;38:185-93.

2. Kisat M, Villegas CV, Onguti S, Zafar SN, Latif A, Efron DT, et al. Predictors of sepsis in moderately severely injured pa- 
tients: an analysis of the National Trauma Data Bank. Surg Infect (Larchmt) 2013;14:62-8.

3. Osborn TM, Tracy JK, Dunne JR, Pasquale M, Napolitano LM. Epidemiology of sepsis in patients with traumatic injury. Crit Care Med 2004;32:2234-40.

4. Wafaisade A, Lefering R, Bouillon B, Sakka SG, Thamm OC, Paffrath T, et al. Epidemiology and risk factors of sepsis after multiple trauma: an analysis of 29,829 patients from the Trauma Registry of the German Society for Trauma Surgery. Crit Care Med 2011;39:621-8.

5. Singer M, Deutschman CS, Seymour CW, Shankar-Hari M, Annane D, Bauer M, et al. The Third International Consensus Definitions for Sepsis and Septic Shock (Sepsis-3). JAMA 2016;315:801-10.

6. Vincent JL, Moreno R, Takala J, Willatts S, De Mendonça A, Bruining H, et al. The SOFA (Sepsis-related Organ Failure Assessment) score to describe organ dysfunction/failure. On behalf of the Working Group on Sepsis-Related Problems of the European Society of Intensive Care Medicine. Intensive Care Med 1996;22:707-10.

7. Levy MM, Fink MP, Marshall JC, Abraham E, Angus D, Cook D, et al. 2001 SCCM/ESICM/ACCP/ATS/SIS International Sepsis Definitions Conference. Crit Care Med 2003;31:1250-6.

8. Park JH, Choi SH, Yoon YH, Park SJ, Kim JY, Cho HJ. Risk factors for sepsis in Korean trauma patients. Eur J Trauma Emerg Surg 2016;42:453-8.

9. Donnelly JP, Safford MM, Shapiro NI, Baddley JW, Wang HE. Application of the Third International Consensus Definitions for Sepsis (Sepsis-3) Classification: a retrospective population-based cohort study. Lancet Infect Dis 2017;17:661-70.
10. Shankar-Hari M, Harrison DA, Rubenfeld GD, Rowan K. Epidemiology of sepsis and septic shock in critical care units: comparison between sepsis-2 and sepsis-3 populations using a national critical care database. Br J Anaesth 2017;119:62636.

11. Besen BA, Romano TG, Nassar AP Jr, Taniguchi LU, Azevedo LC, Mendes PV, et al. Sepsis-3 definitions predict ICU mortality in a low-middle-income country. Ann Intensive Care 2016; 6:107.

12. Lenz A, Franklin GA, Cheadle WG. Systemic inflammation after trauma. Injury 2007;38:1336-45.

13. Tschoeke SK, Ertel W. Immunoparalysis after multiple trauma. Injury 2007;38:1346-57.

14. Angus DC, Linde-Zwirble WT, Lidicker J, Clermont G, Carcillo J, Pinsky MR. Epidemiology of severe sepsis in the United States: analysis of incidence, outcome, and associated costs of care. Crit Care Med 2001;29:1303-10.

15. Martin GS, Mannino DM, Eaton S, Moss M. The epidemiology of sepsis in the United States from 1979 through 2000. N Engl J Med 2003;348:1546-54.

16. Nair GB, Niederman MS. Year in review 2013. Critical care: respiratory infections. Crit Care 2014;18:572.

17. Quenot JP, Binquet C, Kara F, Martinet O, Ganster F, Navellou JC, et al. The epidemiology of septic shock in French intensive care units: the prospective multicenter cohort EPISS study. Crit Care 2013;17:R65

18. Rubano JA, Paccione MF, Rutigliano DN, Vosswinkel JA, McCormack JE, Huang EC, et al. Outcomes following prolonged mechanical ventilation: analysis of a countywide trauma registry. J Trauma Acute Care Surg 2015;78:289-94. 